\title{
Editorial
}

\section{Special issue: XBRL and the future of disclosure}

\author{
International Journal of Disclosure and Governance (2009) 6, 184-185. doi:10.1057/jdg.2009.10
}

The idea behind XBRL, eXtensible Business Reporting Language, is simple. Instead of treating financial information as a block of text - as in a standard internet page or a printed document it provides an identifying tag for each individual item of data. This is computer readable. For example, company net profit has its own unique tag. The introduction of XBRL tags enables automated processing of business information by computer software, cutting out laborious and costly processes of manual re-entry and comparison. Computers can treat XBRL data 'intelligently': they can recognize the information in a XBRL document, select it, analyze it, store it, exchange it with other computers and present it automatically in a variety of ways for users. XBRL greatly increases the speed of handling of financial data, reduces the chance of error and permits automatic checking of information.

(XBRL: www.XBRL.org)

Christopher Cox, the former chairman of the US Securities and Exchange Commission, made the adoption of the eXtensible Business Reporting Language (XBRL) for tagging financial information his signature initiative - a program that came to fruition in February 2009 with the issuance by the SEC of the final rule mandating the use by large US firms of 'Interactive Data To Improve Financial Reporting.' If the proponents of XBRL are to be believed, its adoption not only brings accounting disclosure into the digital age, but it promises to revolutionize capital markets by dramatically reducing the costs of communicating and analyzing financial information. The fact that the SEC committed over US $\$ 50$ million to its interactive data project indicates that XBRL is moving rapidly from theory to practice, a remarkable accomplishment considering that this year marks only the 10th anniversary of its initial proposal by Charlie Hoffman to the American Institute of Certified Public Accountants.

However, it is important to note that despite the scale of this investment, the USA is only catching up with the rest of the world, with
XBRL use and adoption far more advanced in such nations as Australia, China and the Netherlands. Indeed, several of these nations are moving forward with an even more ambitious initiative known as "standard business reporting', in which XBRL is used as the common language to streamline reporting by private companies to the government. Thanks to XBRL, information only has to be entered once to be distributed to all government agencies, eliminating a great deal of duplication and time, and promising to vastly improve efficiency. The pioneer in standard business reporting is the Netherlands, in which it was found that on average the demand by the government for some 200000 pieces of information annually from the typical firm on a wide variety of issues, from taxation to accounting and human resources can be reduced to just 8000 unique pieces of data that is reported just once, to an XBRL-enabled portal, and then distributed to all relevant government agencies without any further action by the firm. This is just one example of the enormous impact that $\mathrm{XBRL}$ is likely to have on society as its use 
becomes ubiquitous - a simply taken for granted part of the background technological infrastructure - and as with much of digital technology at its inception, we can hardly imagine what its ultimate impact is likely to be.

Of course, impact does not imply benefit, and there are undoubtedly many issues concerning XBRL that need careful attention, such as the privacy of easily searchable and communicable digital data. In the USA in particular, there is already great controversy over searches conducted by intelligence agencies in the wake of 9-11 and it would be ironic indeed, if they were to be the most enthusiastic advocates of XBRL adoption.

Given these developments, it is entirely timely and appropriate that this issue of our journal is a special issue entirely devoted to XBRL. We had a very enthusiastic response to the call for papers to this special issue - again, another indication of the increasing attention being paid to XBRL around the world - and we are fortunate that some of the leading practitioners and academic researchers in the field have contributed the papers to this issue. Moreover, several of the authors joined by many other participants took part in the IJDG mini-conference on XBRL that took place on 18 May 2009 in Thessaloniki, Greece as part of the 6th International Conference on Enterprise Systems, Accounting and Logistics.

This is the first time that any journal anywhere has devoted an entire issue to XBRL and your journal will continue to pay close attention to one of the most important developments in disclosure and governance in our times. To kick off the special issue, we are privileged to have a guest editorial by Liv Watson, the Vice Chair of XBRL International and one of the pioneers in the application of technology to disclosure. In her editorial she provides telling evidence of the dramatic impact that XBRL will have on capital markets around the world.

Michael Alles Editor

\title{
Guest Editorial
}

\section{Sorry wrong number - Study finds financial results of 209 listed Indian companies don't add up}

\author{
International Journal of Disclosure and Governance (2009) 6, 185-187. doi:10.1057/jdg.2009.11
}

One thing investors should be able to count on is that audited financial statements reported to public regulatory repositories at least add up, but a recent study shows that is not the case. In a recent study undertaken by IRIS Business Services it was discovered that 209 listed Indian companies had discrepancies in their reports and that the numbers did not add up. IRIS discovered this by converting over 1400 listed Indian companies' primary financial statement into XBRL. It does not really matter whether the quantum of discrepancies are material. The very fact that there are discrepancies is a serious enough matter warranting further examination to prevent such occurrences in the future.

The errors were discovered in the course of creating India's first-ever corporate fundamentals database in XBRL. The project used the taxonomy approved recently by the Institute of Chartered Accountants as a first step toward fullfledged adoption of XBRL in India. It might be unfair to simply blame the auditors, as it is the 